\title{
Barotropic Tide in the Northeast South China Sea
}

\author{
Robert C. Beardsley, Timothy F. Duda, James F. Lynch, Senior Member, IEEE, James D. Irish, Steven R. Ramp, \\ Ching-Sang Chiu, Tswen Yung Tang, Ying-Jang Yang, and Guohong Fang
}

\begin{abstract}
A moored array deployed across the shelf break in the northeast South China Sea during April-May 2001 collected sufficient current and pressure data to allow estimation of the barotropic tidal currents and energy fluxes at five sites ranging in depth from 350 to $71 \mathrm{~m}$. The tidal currents in this area were mixed, with the diurnal $O 1$ and $K 1$ currents dominant over the upper slope and the semidiurnal M2 current dominant over the shelf. The semidiurnal S2 current also increased onshelf (northward), but was always weaker than 01 and $\mathrm{K} 1$. The tidal currents were elliptical at all sites, with clockwise turning with time. The $\mathrm{O1}$ and $\mathrm{K} 1$ transports decreased monotonically northward by a factor of 2 onto the shelf, with energy fluxes directed roughly westward over the slope and eastward over the shelf. The M2 and S2 current ellipses turned clockwise and increased in amplitude northward onto the shelf. The M2 and S2 transport ellipses also exhibited clockwise veering but little change in amplitude, suggesting roughly nondivergent flow in the direction of major axis orientation. The M2 energy flux was generally aligned with the transport major axis with little phase lag between high water and maximum transport. These barotropic energy fluxes are compared with the locally generated diurnal internal tide and high-frequency internal solitary-type waves generated by the M2 flow through the Luzon Strait.
\end{abstract}

Index Terms-Sea measurements, South China Sea, tidal currents, tides.

\section{INTRODUCTION}

$\mathbf{T}$ HE Asian Seas International Acoustics Experiment (ASIAEX) was designed to investigate the influence of water column and bottom variability on the propagation of low-frequency $(50-600 \mathrm{~Hz})$ sound over a low-latitude continental margin. During April-May 2001, an ASIAEX team of Taiwanese and U.S. investigators conducted an intensive multidisciplinary field experiment in the northeast South China Sea (SCS), which featured moored acoustic and physical oceanographic instrumentation; repeat shipboard surveys with SeaSoar; acoustic Doppler current profiler (ADCP); and towed sound sources, bottom mapping, and the collection of surface

Manuscript received September 17, 2003; revised February 26, 2004. This work was supported by the U.S. Office of Naval Research under Grant N00014-98-1-0210 to the Woods Hole Oceanographic Institution and under Grant N00014-01-WR20044 to the Naval Postgraduate School.

R. C. Beardsley, T. F. Duda, J. F. Lynch, and J. D. Irish are with the Woods Hole Oceanographic Institution, Woods Hole, MA 02543 USA (e-mail: rbeardsley @ whoi.edu).

S. R. Ramp and C.-S. Chiu are with the Naval Postgraduate School, Monterey, CA 93943 USA.

T. Y. Tang is with the National Taiwan University, Taipei, Taiwan 106, R.O.C.

Y.-J. Yang is with the Chinese Naval Academy, Tsoying, Kaohsiung, Taiwan, R.O.C.

G. Fang is with the First Institute of Oceanography, State Oceanic Administration, Qingdao, Shandong 266061, China.

Digital Object Identifier 10.1109/JOE.2004.833226 data using satellite advanced very high-resolution radiometer, altimeter, and other microwave sensors [8].

The SCS study area was centered over the shelf break near $21^{\circ} 55^{\prime} \mathrm{N}, 117^{\circ} 20^{\prime} \mathrm{E}$, approximately $370 \mathrm{~km}$ west of the southern tip of Taiwan (Fig. 1). This area was chosen in part for three reasons: 1) large-amplitude high-frequency internal waves generated near the Luzon Strait propagate through the area; 2) the local tidal currents are strong enough to generate significant internal tides; and 3) it was thought that eddies formed by Kuroshio intrusions might dominate subtidal current variability over the continental slope. These processes can all cause large fluctuations in the sound-speed field that directly influence acoustic propagation over the outer shelf on a wide range of time and space scales.

This paper presents a simple description of the surface tide and barotropic tidal currents and energy transport in the study area based on the moored array measurements. Other papers in this Special Issue describe the internal tides, the large-amplitude high-frequency internal waves, and their effects on acoustic propagation.

\section{BAROTROPIC TIDES IN THE SCS}

The dominant tidal constituents in the SCS are the principal lunar diurnal (O1: period $25.82 \mathrm{~h}$ ), principal lunisolar diurnal (K1: period $23.94 \mathrm{~h}$ ), principal lunar semidiurnal (M2: period $12.42 \mathrm{~h}$ ), and, to a lesser extent, the principal solar semidiurnal $(\mathrm{S} 2: 12.00 \mathrm{~h})$. These components are driven primarily by the flux of tidal energy into the SCS from the Pacific Ocean through the Luzon Strait and direct gravitational forcing within the deeper central sector of the sea [10], [5], [4]. The westward flux of $\mathrm{K} 1, \mathrm{O} 1$, and $\mathrm{M} 2$ total (kinetic and potential) energy through the Luzon Strait is significant, roughly 28, 21, and 29 GW, respectively, while the S2 flux is only $3 \mathrm{GW}$. Within the SCS, these waves propagate toward the southwest along the main axis of the sea before entering the shallow Gulf of Tonkin, Gulf of Thailand, and Sunda shelf (Fig. 2). Due to the complex bathymetry in these shallow areas and the near-resonant diurnal response of the two gulfs, the resulting cotidal charts exhibit local amplification and complex structure, with some areas dominated by the diurnal components $\mathrm{K} 1$ or $\mathrm{O} 1$ and other areas by the semidiurnal M2 tide.

Tides in the ASIAEX study region are strongly influenced by the nearby presence of Taiwan and the Taiwan Strait (Fig. 2). Taiwan is located on the outer Chinese continental shelf and the Taiwan Strait connects the SCS with the East China Sea (ECS) along the shelf. The strait is roughly $160 \mathrm{~km}$ wide at its narrowest point and has a shallow and irregular bottom with a mean depth of roughly $70 \mathrm{~m}$. A significant fraction $(\sim 28 \%)$ 

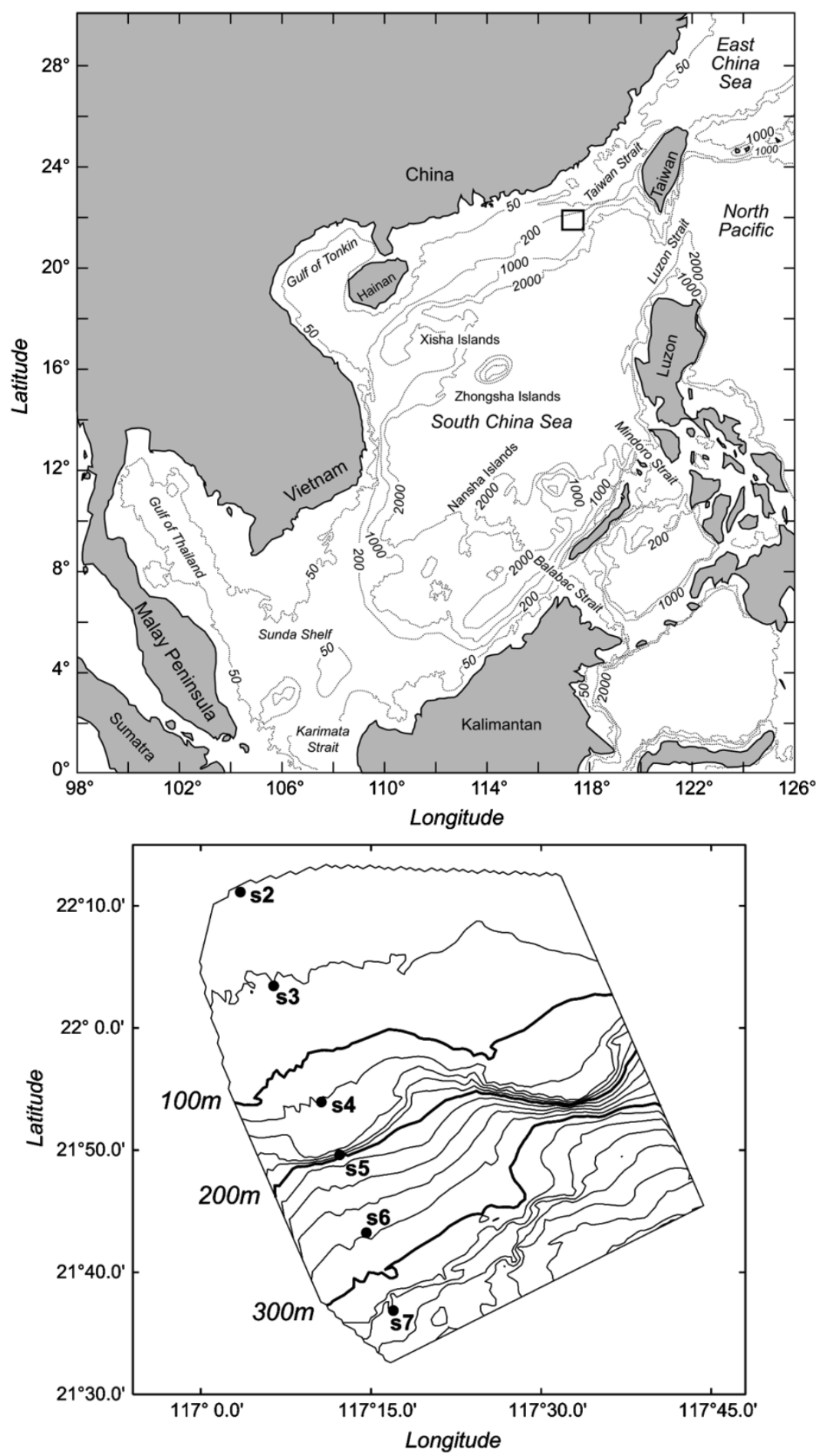

Fig. 1. Upper panel: simplified map of the SCS, showing the main topographic features and the location of the 2001 ASIAEX study area (hollow square) in the northeast and the adjacent North Pacific and East China Sea (ECS). The 50-, 200-, 1000-, and 2000-m isobaths are shown. Lower panel: the locations of the six ASIAEX mooring sites (s2-s7) and local topography. The depth contour interval is $20 \mathrm{~m}$, with the 100-, 200-, and 300-m isobaths denoted by the heavy lines.

of the M2 flux entering through the Luzon Strait is refracted clockwise around Taiwan and propagates like a Kelvin wave toward the northeast along the west coast of Taiwan [3], [4], [7]. A larger M2 Kelvin wave is forced along the Chinese coast through the Taiwan Strait from the ECS, presumably due in part to the counterclockwise refraction of the incident M2 wave around the northern end of Taiwan and the presence of the Chinese coast [11]. The resulting M2 tide shows a rapid phase increase over the outer shelf west of Taiwan and maximum surface heights along the Chinese coast within the Taiwan Strait. In sharp contrast, very little $(<1 \%)$ of the $\mathrm{O} 1$ and $\mathrm{K} 1$ energy flux from the Luzon Strait is turned northward around Taiwan and the diurnal tidal forcing from the ECS is also very weak. Both $\mathrm{O} 1$ and $\mathrm{K} 1$ exhibit a relatively small change in phase and only a moderate increase in surface height northward toward the Chinese coast. 

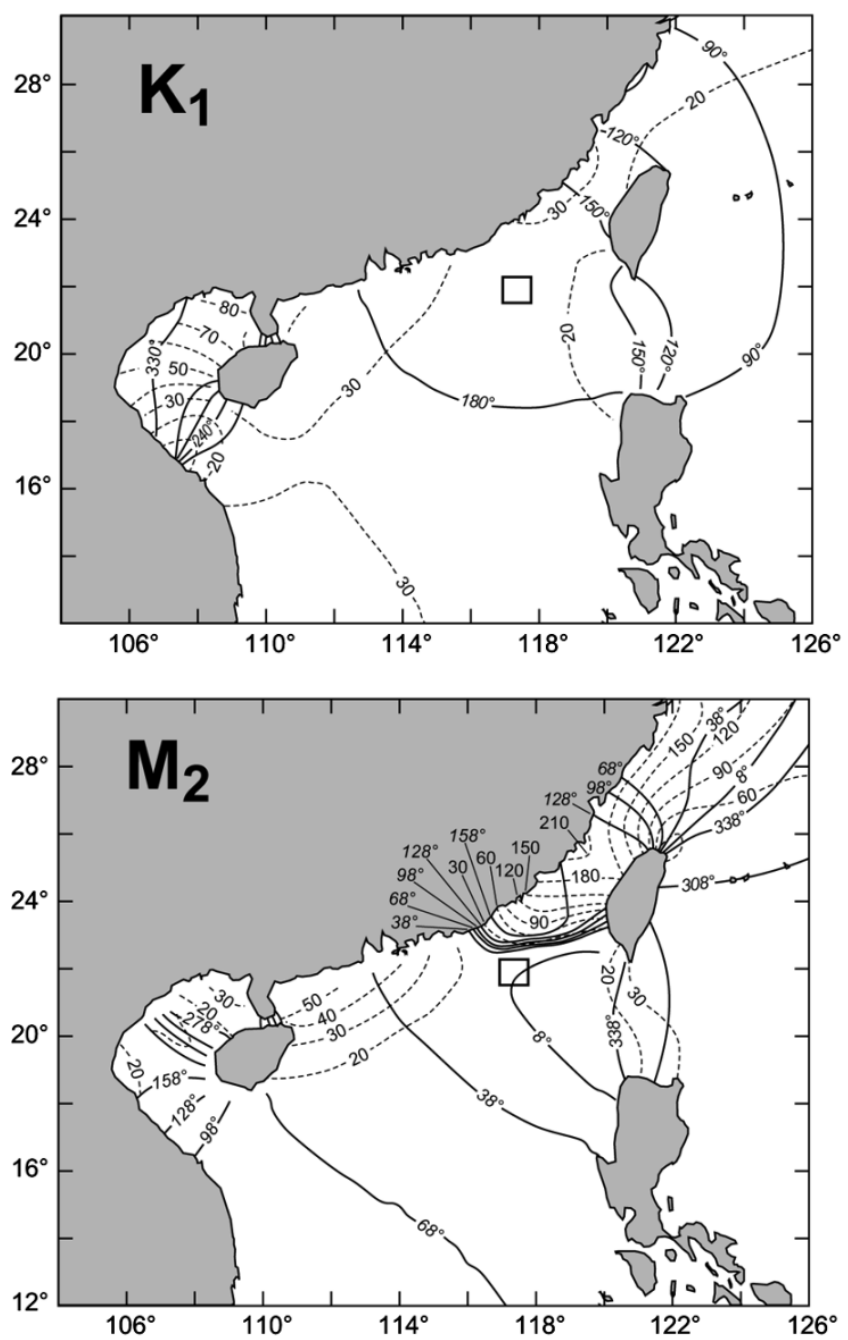

Fig. 2. (a) Cotidal map for K1, based on [4] within the SCS and [11] and [7] around Taiwan and east and north. Amplitude contours $(10 \mathrm{~cm})$ are shown by dashed lines and the Greenwich phase lag (degrees) is shown by solid lines. The ASIAEX study area is within the box located west of Taiwan. (b) Cotidal map for M2, based on [4] within the SCS and [11] and [7] around Taiwan and the east and north. Amplitude contours $\left(10 \mathrm{~cm}\right.$ west of $116^{\circ} \mathrm{W}, 30 \mathrm{~cm}$ east of $116^{\circ} \mathrm{W}$, and north of $22^{\circ} \mathrm{N}$ ) are shown by dashed lines and the Greenwich phase lag (degrees) is shown by solid lines. The ASIAEX study area is within the box located west of Taiwan.

\section{DATA SET}

As part of the ASIAEX 2001 SCS field effort, one RD Instruments 150-kHz and seven RDI 300-kHz ADCPs were deployed at seven sites in a straight transect starting in deep water at site s8 and running toward $340^{\circ} \mathrm{N}$ to the shallow site s2, with another site (s1) located approximately $48 \mathrm{~km}$ to the east of $\mathrm{s} 3$ [Fig. 1, Tables I and II(A)]. At s2, the ADCP was deployed on the bottom in a trawl-resistant bottom mooring. At all other sites, the ADCPs were deployed looking upward with subsurface flotation to collect current profile data from near-surface to as close to the bottom as feasible. At the 350-m-deep s7 site, Aanderaa RCM8 current meters were deployed at depths of 153 , 211 , and $314 \mathrm{~m}$ to augment the ADCP current measurements in the vertical. Unfortunately, the $\mathrm{s} 8$ ADCP returned no data and the s1 mooring was lost, presumably to fishing activities. The s6 ADCP returned good data, but was not used in this analysis due to the lack of additional current measurements below the ADCP at $110 \mathrm{~m}$. Bottom pressure was measured at s2, s3, and s7 with an ADCP strain-gauge sensor at s2 and SBE Paroscientific tide gauges at s3 and s7 [Table II(B)].

For comparison, regional surface height data were extracted from the global ocean tide model TPXO.6.0 [2]. TPXO.6.0 represents an optimal fit (in a least-squares sense) of the TOPEX/Poseidon (TP) altimeter crossover and selected along-track data to the Laplace tidal equations with the resultant constituent complex amplitudes resolved on a $1 / 4^{\circ}$ global grid. Because of the coarse spacing of the TP ground track relative to the complex bathymetry in the northeast SCS around the ASIAEX study area, we might expect that the TPXO.6.0 height values will exhibit larger errors in the study area than in the open ocean (where the errors are of order $0.8-1.4 \mathrm{~cm}$ for the main constituents).

\section{Data Processing}

The basic ADCP and Aanderaa current data were first edited to remove occasional unrealistic extreme values (speeds > $10 \mathrm{~m} / \mathrm{s}$ ), which were replaced by linear interpolation. Then the depth-averaged velocity components $U$ and $V$ were computed using simple block averaging in the vertical, where the velocity in each good ADCP measurement depth bin is assumed to be constant with height over that depth bin and the velocities in the top and bottom good ADCP measurement depth bins were extended without change to the ocean surface and bottom, respectively. The $150-\mathrm{kHz}$ ADCP at s5 was set with 8-m depth bins and the other ADCPs used 4-m depth bins. At s7, the good ADCP profile data were merged with the deeper Aanderaa current data to compute the depth average [see Table II(A) for depth coverage, sample intervals, and other pertinent information].

The bottom pressure data were processed in a similar way. The s3 anchor was dragged almost $3 \mathrm{~km}$ west on May 5, while the s7 anchor was moved four times during May 7-9 by very large solitary-type internal waves from the Luzon Strait [1]. These position changes resulted in small but noticeable abrupt changes in mean depth. After correcting for these offsets, the mean and linear trend was subtracted from each pressure record to produce time series of bottom pressure fluctuations [Table II(B)].

Harmonic tidal analysis was done on the final edited $U, V$, and bottom pressure time series using the MATLAB program T_TIDE [12]. Due to the shortness of our time series, inference was used to separate the principal constituents from nearby weaker but still-energetic constituents. We chose for our reference station Shanwei, located on the Chinese coast to the west of the region of rapid change in M2 amplitude and phase shown in Fig. 2(b). Harmonic analysis of a 16-year tide record at Shanwei (Table III) shows that the minor constituents Q1, P1, N2, and K2 range in amplitude from $19 \%$ to $31 \%$ of their nearby major constituent $\mathrm{O} 1, \mathrm{~K} 1, \mathrm{M} 2$, and $\mathrm{S} 2$ and thus need inclusion. T_TIDE was thus run with inference (based on Table III) and linear trend removal. The Rayleigh criterion, normally 1.0 , was set to 0.98 for direct separation of $\mathrm{M} 2$ and $\mathrm{S} 2$ in the $\mathrm{s} 3 \mathrm{U} / \mathrm{V}$ analysis and to 0.95 for direct separation of Q1 and $\mathrm{O} 1$ and $\mathrm{N} 2$ and $\mathrm{M} 2$ in the s2 and s5 $U / V$ and s2 bottom pressure analyses. To illustrate the observed variability and results of harmonic analysis, in Fig. 3 
TABLE I

ASIAEX ADCP Mooring Positions. Mooring s1 Was Lost and s8 RetUrned no Data. The s2 ADCP Was Bottom Mounted; the Rest Were DePloyed ABOve THE ACOUSTIC RelEASE ON THE MoORING. THE RDI ADCP Model (WH = broadband Workhorse; NB = narrowband) AND THE GROUP RESPONSIBLE FOR THE MOORED INSTRUMENTATION ARE INCLUDED

\begin{tabular}{c|c|c|c|c}
\hline Site & ${\text { Latitude }\left({ }^{\circ} \mathbf{N}\right)}^{\prime}$ & Longitude $\left({ }^{\circ} \mathbf{E}\right)$ & ADCP & Source \\
\hline s1 (lost) & $22^{\circ} 05.360^{\prime}$ & $117^{\circ} 34.430^{\prime}$ & $300 \mathrm{kHz} \mathrm{WH}$ & WHOI/NPS \\
\hline $\mathrm{s} 2$ (adcp-71) & $22^{\circ} 11.140^{\prime}$ & $117^{\circ} 03.490^{\prime}$ & $300 \mathrm{kHz} \mathrm{WH}$ & NTU \\
\hline $\mathrm{s} 3($ env-85) & $22^{\circ} 03.445^{\prime}$ & $117^{\circ} 06.423^{\prime}$ & $300 \mathrm{kHz} \mathrm{WH}$ & WHOI/NPS \\
\hline $\mathrm{s} 4($ env-120) & $21^{\circ} 53.944^{\prime}$ & $117^{\circ} 10.619^{\prime}$ & $300 \mathrm{kHz} \mathrm{WH}$ & WHOI/NPS \\
\hline $\mathrm{s} 5$ (env-184) & $21^{\circ} 49.616^{\prime}$ & $117^{\circ} 12.240^{\prime}$ & $150 \mathrm{kHz} \mathrm{NB}$ & WHOI/UMaine \\
\hline $\mathrm{s} 6($ adcp-275) & $21^{\circ} 43.240^{\prime}$ & $117^{\circ} 14.600^{\prime}$ & $300 \mathrm{kHz} \mathrm{WH}$ & NTU \\
\hline $\mathrm{s} 7$ (env-350) & $21^{\circ} 36.871^{\prime}$ & $117^{\circ} 16.975^{\prime}$ & $300 \mathrm{kHz} \mathrm{WH}$ & WHOI/NPS \\
\hline $\mathrm{s} 8($ adcp-800) & $20^{\circ} 52.332^{\prime}$ & $117^{\circ} 34.878^{\prime}$ & No Data & NTU \\
\hline
\end{tabular}

TABLE II(A)

ADCP Deployment Information, Vertical Coverage (Depth of DeEpest and Shallowest Depth Bins With Good Data), Depth Bin Size, Ensemble Interval, Start Time, Rayleigh Criterion, and Record Length Used in the Barotropic Tidal Analysis. The s7 Mooring Also SUPPORTED THE AANDERAA RCM8 CURRENT METERS AT 313.6, 211.3, AND $152.8 \mathrm{~m}$

\begin{tabular}{c|c|c|c|c|c|c|c}
\hline Site & $\begin{array}{c}\text { Water } \\
\text { Depth } \\
(\mathbf{m})\end{array}$ & $\begin{array}{c}\text { ADCP } \\
\text { Coverage } \\
\left(\mathbf{z}_{\mathbf{B}}-\mathbf{z}_{\mathbf{T}}\right)\end{array}$ & $\begin{array}{c}\text { Depth Bin } \\
(\mathbf{m})\end{array}$ & $\begin{array}{c}\text { Ensemble } \\
\text { Interval } \\
(\mathbf{m i n})\end{array}$ & $\begin{array}{c}\text { Start } \\
\text { Time } \\
(\mathbf{U T})\end{array}$ & $\begin{array}{c}\text { Rayleigh } \\
\text { Criterion }\end{array}$ & $\begin{array}{c}\text { Record } \\
\mathbf{\text { Length }} \\
(\mathbf{d a y s})\end{array}$ \\
\hline $\mathrm{s} 2$ & 71 & $64.0-8.0$ & 4 & 2.0 & $\begin{array}{c}\text { April 20 } \\
16: 00: 00\end{array}$ & 0.95 & 26.58 \\
\hline $\mathrm{s3}$ & 85 & $74.5-10.5$ & 4 & 1.0 & $\begin{array}{c}\text { April 20 } \\
13: 11: 00\end{array}$ & 0.98 & 14.64 \\
\hline s4 & 120 & $98.5-18.5$ & 4 & 1.0 & $\begin{array}{c}\text { April 21 } \\
10: 50: 02\end{array}$ & 1.00 & 27.82 \\
\hline s5 & 184 & $165.0-29.0$ & 8 & 2.0 & $\begin{array}{c}\text { April 21 } \\
06: 07: 43\end{array}$ & 0.95 & 27.14 \\
\hline s7 & 350 & $94.5-10.5$ & 4 & 1.0 & $\begin{array}{c}\text { April 21 } \\
03: 30: 00\end{array}$ & 1.00 & 27.84 \\
\hline
\end{tabular}

TABLE II(B)

BOTTOM-PRESSURE MEASUREMENT INFORMATION, SAMPLE INTERVAL, StART Time, RAYLEIGH CRITERION, AND RECORD LENGTH USED IN THE TIDAL ANALYSIS

\begin{tabular}{c|c|c|c|c}
\hline Site & $\begin{array}{c}\text { Sample } \\
\text { Interval } \\
\text { (min) }\end{array}$ & $\begin{array}{c}\text { Start Time } \\
\text { (UT) }\end{array}$ & $\begin{array}{c}\text { Rayleigh } \\
\text { Criterion }\end{array}$ & $\begin{array}{c}\text { Record } \\
\text { Length } \\
\text { (days) }\end{array}$ \\
\hline s2 & 2.0 & April 20 16:00:00 & 0.95 & 26.58 \\
\hline s3 & 5.0 & April 20 13:15:00 & 1.00 & 31.03 \\
\hline s7 & 5.0 & April 21 02:20:00 & 1.00 & 27.89 \\
\hline
\end{tabular}

TABLE III

Amplitude and Phase of the PRincipal Tidal Constituents at THE Chinese Coastal RefERENCE Station SHANwei $\left(22^{\circ} 45^{\prime} \mathrm{N}\right.$, $115^{\circ} 21^{\prime}$ E). THeSE HaRmonic ANALYSIS VALUES ARE BASED ON A 16-YR-LONG RECORD AT THIS STATION

\begin{tabular}{cccc}
\hline Constituent & Period (hr) & Height (cm) & Phase (G) \\
Q1 & 26.8684 & 5.09 & 121.45 \\
O1 & 25.8193 & 26.40 & 137.49 \\
P1 & 24.0659 & 10.24 & 172.83 \\
K1 & 23.9345 & 32.52 & 176.29 \\
N2 & 12.6584 & 6.18 & 15.50 \\
M2 & 12.4206 & 27.60 & 22.42 \\
S2 & 12.0000 & 11.00 & 35.67 \\
K2 & 11.9672 & 3.21 & 35.99 \\
\hline
\end{tabular}

we plot the basic and tidal $U$ and $V$ time series at s5. To simplify this figure, the basic $U$ and $V$ series have been decomposed into subtidal (periods $>33 \mathrm{~h}$ ) and tidal and above (periods $<33 \mathrm{~h}$ ) components. The occasional spikes in the basic series are caused by the large-amplitude high-frequency internal waves that propagate through the ASIAEX array [1]. The tidal series includes all constituents with a signal-to-noise ratio (SNR) $\geq 2$.
V. RESUlts

\section{A. Elevation}

$\mathrm{O} 1$ and $\mathrm{K} 1$ are the dominant surface tides in the ASIAEX study area, with mean amplitudes of 24.0 and $25.2 \mathrm{~cm}$, respectively, and Greenwich phase lags of $130^{\circ}$ and $170^{\circ}$ (Table IV). As suggested by the model K1 cotidal chart in Fig. 2(a), there is no significant change in amplitude or phase lag over the bottom-pressure array. The measured $\mathrm{O} 1$ and $\mathrm{K} 1$ amplitudes differ only slightly from those extrapolated from TPXO.6.0 (1.0 and $-0.4 \mathrm{~cm}$, respectively) and the measured $\mathrm{O} 1$ and $\mathrm{K} 1$ phase lags agree to within $1.4^{\circ}$ with TPXO.6.0. The combined $\mathrm{K} 1$ and $\mathrm{O} 1$ surface tides account for about $82 \%$ of the fitted tidal variance (i.e., defined here as the total variance of all fitted constituents with SNRs $\geq 2$ ) at the three sites.

The M2 and S2 surface tides are smaller, with mean amplitudes of 12.2 and $4.7 \mathrm{~cm}$, respectively (Table IV). While there is no significant change in amplitude across the array, both constituents exhibit a northward increase in phase lag, consistent with northward propagation, as shown in the model M2 cotidal chart in Fig. 2(b). The measured M2 phase speed between s7 and $\mathrm{s} 2$ is $17.3 \pm 3.0 \mathrm{~m} / \mathrm{s}$ (based on the distance between $\mathrm{s} 2$ and s7 and the difference in phase lag). Integration of the reciprocal phase speed $\sqrt{g h}\left(1+f^{2} / \sigma^{2}\right)^{1 / 2}$ of a long Sverdrup plane wave between $\mathrm{s} 7$ and s 2 gives a mean phase speed of $38.8 \mathrm{~m} / \mathrm{s}$. This is significantly larger than measured, indicating that the M2 is not a simple plane wave propagating northward through the study area, but is strongly influenced by the regional three-dimensional (3-D) bathymetry associated with the shelf and Taiwan. 

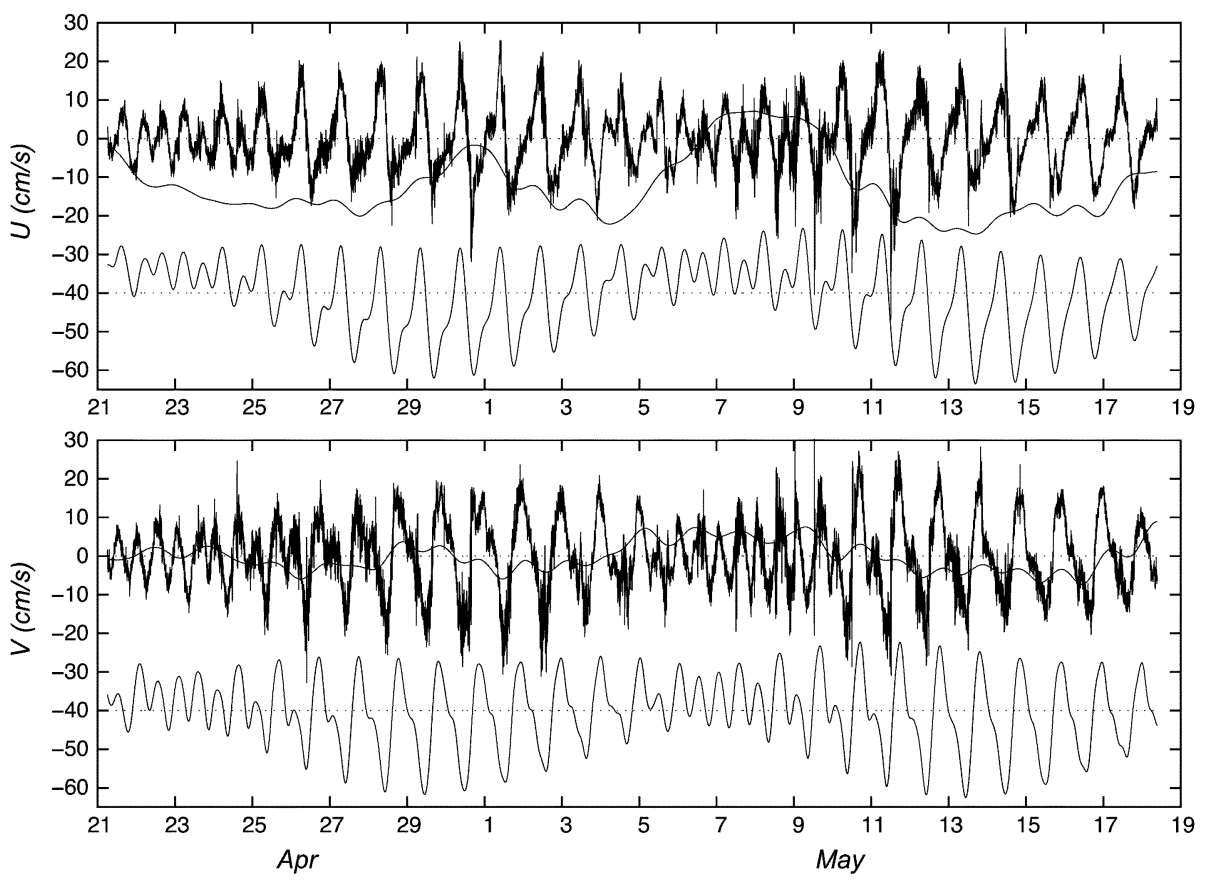

Fig. 3. Upper panel: basic s5 $U$ time series (decomposed into subtidal and tidal components for this figure) plotted with respect to $0 \mathrm{~cm} / \mathrm{s}$ and the predicted $U$ (from harmonic analysis) plotted with respect to $-40 \mathrm{~cm} / \mathrm{s}$. Lower panel: the same for $V$.

TABLE IV

Principal Tidal Height Constituents at s2, s3, And s7 With $\pm 95 \%$ Confidence Limits Based on the Analysis of the Bottom Pressure Records. The Height Is Given in cm and the Phase Lag in Degrees Relative to Greenwich. The Percent Variance Is the Contribution of That Constituent to the Fitted Tidal Variance at Each Site. The TP Height and Greenwich Phase Lag at Each Site EXtRapolated From TPXO.6.0 ARE Listed IN THE LAST Two COLUMNS

\begin{tabular}{c|c|c|c|c|c}
\hline O1 & Height (cm) & Phase (G) & \% Var & TP Height (cm) & TP Phase (G) \\
\hline s2 & $24.2 \pm 0.5$ & $131.1 \pm 1.2$ & 40.2 & 23.1 & 130.8 \\
\hline s3 & $24.2 \pm 0.5$ & $130.0 \pm 1.1$ & 40.0 & 22.8 & 129.9 \\
\hline s7 & $23.7 \pm 1.0$ & $127.4 \pm 2.4$ & 37.8 & 23.1 & 130.2 \\
\hline \multicolumn{5}{|c}{} \\
\hline K1 & Height (cm) & Phase (G) & \% Var & TP Height (cm) & TP Phase (G) \\
\hline s2 & $25.1 \pm 0.5$ & $169.2 \pm 1.3$ & 42.4 & 26.0 & 169.4 \\
\hline s3 & $25.0 \pm 0.5$ & $170.8 \pm 1.0$ & 42.6 & 25.8 & 168.5 \\
\hline s7 & $25.4 \pm 1.2$ & $170.6 \pm 2.4$ & 43.2 & 24.9 & 168.4 \\
\hline \multicolumn{7}{|c}{} \\
\hline M2 & Height (cm) & Phase (G) & \% Var & TP Height (cm) & TP Phase (G) \\
\hline s2 & $11.9 \pm 1.0$ & $36.8 \pm 4.2$ & 9.5 & 11.7 & 45.6 \\
\hline s3 & $11.8 \pm 0.7$ & $21.8 \pm 3.2$ & 9.4 & 12.7 & 26.0 \\
\hline s7 & $13.0 \pm 0.8$ & $5.3 \pm 3.6$ & 11.4 & 15.2 & -2.7 \\
\hline \multicolumn{7}{|c|}{ Phase (G) } & \% Var & TP Height (cm) & TP Phase (G) \\
\hline S2 & Height (cm) & $28.7 \pm 13.8$ & 1.2 & 4.9 & 17.1 \\
\hline s2 & $4.2 \pm 1.0$ & $25.8 \pm 9.3$ & 1.5 & 5.4 & 10.6 \\
\hline s3 & $4.6 \pm 0.7$ & $19.6 \pm 8.6$ & 1.8 & 6.1 & 0.1 \\
\hline s7 & $5.2 \pm 0.8$ & \multicolumn{5}{|c}{}
\end{tabular}

The M2 and S2 amplitudes and M2 phase lag differ slightly from TPXO.6.0 (1.0 and $\left.0.8 \mathrm{~cm} ; 1.7^{\circ}\right)$ while the $\mathrm{S} 2$ phase lag difference is $15.4^{\circ}$. The TPXO.6.0 northward M2 phase speed between $\mathrm{s} 2$ and $\mathrm{s} 7$ is $11.3 \mathrm{~m} / \mathrm{s}$, about $65 \%$ of the measured value. Given the relatively coarse spacing of the TP data in the study area used to compute TPXO.6.0 and the rapid spatial variation in M2 (and S2) amplitude and phase in the study area shown by [4] and [7] in model studies, the degree of agreement between the measured and TPXO.6.0 surface tides is encouraging. The combined measured M2 and S2 surface tides account for about $12 \%$ of the fitted tidal variance at the three sites. Taken together, the O1, K1, M2, and S2 account for about $94 \%$ of the fitted tidal variance at each site.

\section{B. Current}

The dominant barotropic tidal currents in the ASIAEX study area are the two primary diurnal constituents $\mathrm{O} 1$ and $\mathrm{K} 1$ and the two semidiurnal constituents M2 and S2 (Table V). The K1 and $\mathrm{O} 1$ have similar ellipse characteristics (Fig. 4), with a clockwise turning of the major axis between $\mathrm{s} 7$ and $\mathrm{s} 5$ and less variation in orientation between s5 and s2. The major axes appear to be oriented roughly $45^{\circ}$ across the local isobaths, resulting in comparable cross- and along-isobath components. Both diurnal velocity vectors rotate clockwise with time at stations s2 to s5. At s7, the O1 vector turns clockwise while the K1 turns counterclockwise; however, the semiminor axis of both diurnal 
TABLE V

Tidal Current Ellipse Parameters With $\pm 95 \%$ Confidence Limits. Units: cm/s; Orientation Given In Degrees Counterclockwise From the EAST and Greenwich Phase Lag in Degrees. The Last Column Indicates the Percent Contribution of Each Constituent to the Total

Tidal Band Variance at That Mooring Site. These Constituents Contribute 71\%-93\% of the Tidal Band Variance

\begin{tabular}{|c|c|c|c|c|c|}
\hline 01 & Major $(\mathrm{cm} / \mathrm{s})$ & Minor $(\mathrm{cm} / \mathrm{s})$ & Inclination & Phase (G) & $\%$ Var \\
\hline $\mathrm{s} 2$ & $6.3 \pm 1.1$ & $-3.9 \pm 1.2$ & $123.5 \pm 22.0$ & $22.9 \pm 21.3$ & 11.3 \\
\hline s3 & $6.8 \pm 1.0$ & $-3.9 \pm 1.2$ & $129.4 \pm 17.0$ & $29.8 \pm 17.9$ & 11.5 \\
\hline s4 & $8.9 \pm 2.7$ & $-4.8 \pm 2.0$ & $121.5 \pm 22.5$ & $19.6 \pm 25.3$ & 23.7 \\
\hline s5 & $9.4 \pm 1.5$ & $-3.0 \pm 1.8$ & $125.4 \pm 12.2$ & $27.0 \pm 10.5$ & 28.5 \\
\hline s7 & $6.3 \pm 0.8$ & $-0.7 \pm 1.0$ & $173.7 \pm 9.5$ & $55.9 \pm 6.9$ & 42.2 \\
\hline K1 & Major $(\mathrm{cm} / \mathbf{s})$ & Minor $(\mathbf{c m} / \mathbf{s})$ & Inclination & Phase (G) & $\%$ Var \\
\hline s2 & $7.7 \pm 1.2$ & $-2.4 \pm 1.3$ & $135.9 \pm 10.9$ & $63.1 \pm 10.3$ & 13.5 \\
\hline s3 & $8.6 \pm 1.2$ & $-4.6 \pm 1.1$ & $145.7 \pm 11.0$ & $71.8 \pm 12.0$ & 17.9 \\
\hline s4 & $11.9 \pm 2.2$ & $-5.8 \pm 2.7$ & $137.5 \pm 17.4$ & $76.4 \pm 19.4$ & 40.4 \\
\hline s5 & $10.2 \pm 1.6$ & $-3.8 \pm 1.5$ & $137.4 \pm 11.8$ & $84.3 \pm 12.8$ & 34.4 \\
\hline s7 & $4.9 \pm 0.8$ & $1.2 \pm 0.9$ & $161.6 \pm 11.0$ & $101.6 \pm 10.0$ & 26.2 \\
\hline M2 & Major (cm/s) & Minor $(\mathrm{cm} / \mathrm{s})$ & Inclination & Phase (G) & $\%$ Var \\
\hline s2 & $16.6 \pm 1.1$ & $-7.3 \pm 0.8$ & $82.2 \pm 3.6$ & $32.4 \pm 5.0$ & 68.7 \\
\hline s3 & $12.9 \pm 2.0$ & $-6.9 \pm 1.3$ & $96.8 \pm 11.4$ & $34.5 \pm 13.5$ & 40.1 \\
\hline s4 & $9.0 \pm 1.3$ & $-5.2 \pm 1.2$ & $116.7 \pm 11.7$ & $37.8 \pm 14.1$ & 24.9 \\
\hline s5 & $5.5 \pm 0.8$ & $-4.9 \pm 0.6$ & $82.2 \pm 46.7$ & $54.6 \pm 48.5$ & 15.8 \\
\hline s7 & $3.6 \pm 0.3$ & $-2.2 \pm 0.4$ & $153.1 \pm 9.6$ & $352.2 \pm 8.6$ & 18.8 \\
\hline S2 & Major (cm/s) & $\operatorname{Minor}(\mathbf{c m} / \mathbf{s})$ & Inclination & Phase (G) & $\%$ Var \\
\hline s2 & $4.0 \pm 1.2$ & $-2.3 \pm 0.8$ & $80.8 \pm 21.1$ & $84.1 \pm 26.9$ & 4.4 \\
\hline s3 & $2.8 \pm 2.0$ & $-1.2 \pm 1.2$ & $88.1 \pm 36.8$ & $65.1 \pm 57.5$ & 1.7 \\
\hline s4 & $3.2 \pm 1.3$ & $-2.4 \pm 1.1$ & $84.2 \pm 53.9$ & $113.6 \pm 63.7$ & 3.7 \\
\hline s5 & $2.2 \pm 0.8$ & $-0.9 \pm 0.6$ & $109.2 \pm 23.4$ & $99.6 \pm 28.9$ & 1.7 \\
\hline s7 & $1.1 \pm 0.3$ & $-0.8 \pm 0.4$ & $163.6 \pm 48.3$ & $17.3 \pm 47.7$ & 1.8 \\
\hline
\end{tabular}

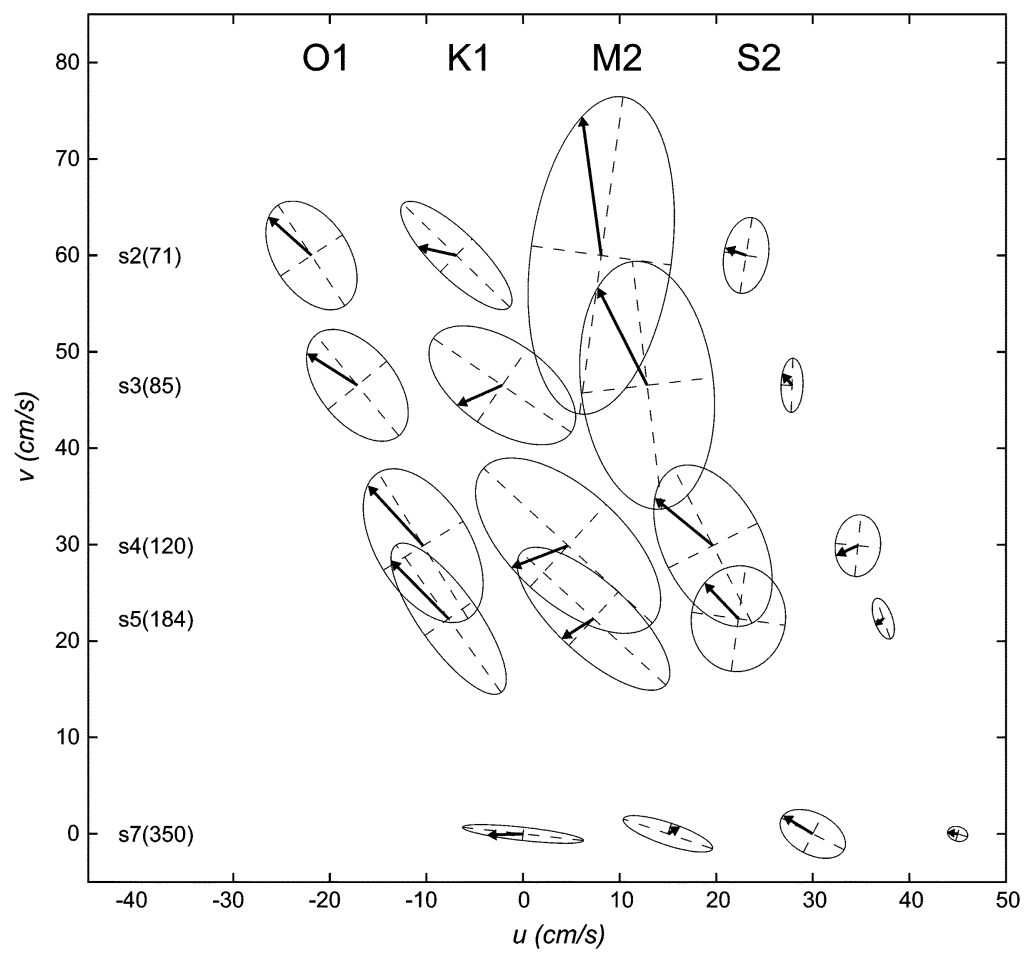

Fig. 4. O1, K1, M2, and S2 tidal ellipses at the ASIAEX mooring sites plotted with North up, offset origins, and a common velocity scale to facilitate comparison. The major and minor axes denoted by dashed lines and the direction of the velocity vector at zero Greenwich phase by the vector drawn from the ellipse center. The centers of the ellipses for each constituent are plotted to reflect the geographical positions of the mooring sites. 


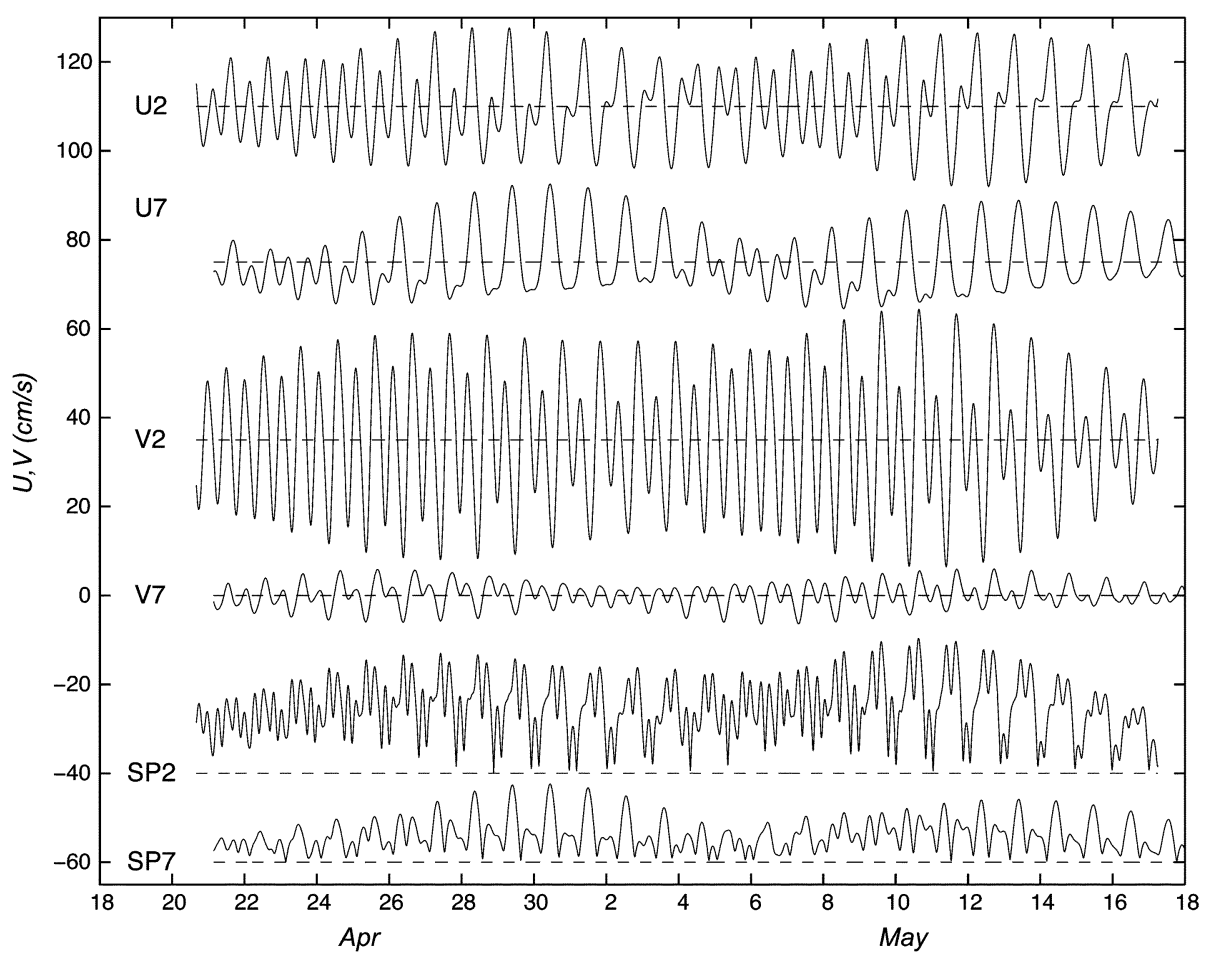

Fig. 5. Time series of tidal $U$ and $V$ components at s2 and s7 plotted with the same speed scale. To facilitate comparison, the $U$ component at s2 (U2) and s7 (U7) are plotted at the top and the $V$ component at s2 (V2) and s7 (V7) are plotted below. The tidal speed at s2 (SP2) and s7 (SP7) are shown at the bottom.

constituents is poorly resolved at s7. The current amplitudes increase from s7 to s5 (O1) and s4 (K1), then decrease toward s2. The maximum amplitudes thus occur over the shelf break.

The M2 is the dominant semidiurnal constituent, with current amplitude roughly 2-3 times larger than S2. Despite this magnitude difference, both M2 and S2 exhibit a significant clockwise turning of the major axis orientation between $\mathrm{s} 7$ and $\mathrm{s} 2$, with the major axes at $\mathrm{s} 3$ and $\mathrm{s} 2$ oriented roughly perpendicular to the local isobaths, causing the cross-isobath component to exceed the along-isobath component by at least $50 \%$. Both semidiurnal velocity vectors rotate clockwise in time at all sites and both M2 and S2 current ellipses increase in size as the water depth decreases from s7 to s2. While the $\mathrm{K} 1$ and $\mathrm{O} 1$ current amplitudes exceed the $\mathrm{S} 2$ current amplitudes at all sites, the M2 becomes larger than the $\mathrm{K} 1$ at $\mathrm{s} 3$ and larger than $\mathrm{O} 1$ at $\mathrm{s} 4$, so that at $\mathrm{s} 2$, the $\mathrm{M} 2$ is the dominant tidal current by a factor of 2 or more, accounting for about $65 \%$ of the total tidal band variance at that site.

As a result of these changes in the amplitude and orientation between the deep s7 and shallow s2 sites, the character of the resulting tidal currents varies across the shelf break. To illustrate this, the $U$ and $V$ tidal currents at s7 and s2 are plotted together in Fig. 5. The onshelf increase in M2 enhances the semidiurnal nature of the $U$ and $V$ currents at $\mathrm{s} 2$ from the primarily diurnal nature at s7. This is especially clear in the comparison of tidal current speed at s2 and s7, shown in Fig. 5. The twin speed peaks per M2 cycle can be seen throughout the $\mathrm{s} 2$ record, while missing from most of the $\mathrm{s} 7$ record. The mean speed at $\mathrm{s} 7$ is $6.1 \pm 3.4 \mathrm{~cm} / \mathrm{s}$ with a peak speed of $17.6 \mathrm{~cm} / \mathrm{s}$. At s2, the mean speed is $14.8 \pm 6.1 \mathrm{~cm} / \mathrm{s}$, with a peak speed of $30.4 \mathrm{~cm} / \mathrm{s}$, roughly double that at s7.

The O1, K1, M2, and S2 components account for $80 \%-93 \%$ of the total tidal band variance at each mooring site except at $\mathrm{s} 3$ where about $71 \%$ is due to these components.

\section{Transport}

The tidal transports can be easily computed for each constituent by simply multiplying $U$ and $V$ by the water depth at each site. The resulting transport ellipses are shown in Fig. 6. The diurnal transports exhibit a strong decrease between s7 and s2, consistent with the decrease in water depth and the decrease in current amplitude north of s5. The semidiurnal constituents exhibit a much more uniform transport amplitude as a function of latitude, suggesting that the northward M2 transport is approximately constant (nondivergent) in this area.

\section{Energy Flux}

The horizontal tidal energy flux for each constituent is defined as $\vec{F}=\rho g\langle\vec{U} \zeta\rangle$, where $\rho$ is the fluid density, $g$ is gravity, $\vec{U}$ is the barotropic tidal transport vector, $\zeta$ is the surface tidal elevation, and the brackets denote an average over time. The flux $\vec{F}$ was computed using the harmonic analysis results for the main constituents at s2, s3, and s7, where both current and bottom pressure were measured. Since the surface tides varied slowly over the study area, linear interpolation was used to estimate the surface elevation amplitude and phase for the main constituents at $\mathrm{s} 4$ and $\mathrm{s} 5$, and the energy flux computed using these values and the measured transports at these two sites. The flux is a maximum when high water occurs during maximum flow (i.e., when the transport vector is aligned with the major axis) and a minimum when high water occurs $\pm 90^{\circ}$ later during minimum flow (the vector aligned with the minor axis). Table VI lists the flux components, amplitude and direction, the difference in the flux vector and transport major axis directions, the phase difference between surface elevation and transport, and the ratio of the computed flux to the maximum possible flux (i.e., when elevation and transport are in phase). 
TABLE VI

Energy Flux EAst $\left(\boldsymbol{F}_{\boldsymbol{X}}\right)$ And North $\left(\boldsymbol{F}_{\boldsymbol{Y}}\right)$ Components, Amplitude $(\boldsymbol{F})$, Direction With Respect to EASt $(\theta)$, Angle Between the Transport Major Axis and the Energy Flux Vector $(\Delta \theta)$, Phase DifFerence Between Surface Height and Transport $(\Delta \phi)$ and the Ratio $($ In PeRcent) of The Computed Flux $(F)$ to the MaXimum Possible Flux ( $F_{\text {Max }}$ ) (I.E., With Surface Height and Transport in Phase) For the Primary Tidal CONSTITUENTS AT EACH Site. UnITS: $10 \mathrm{~kW} / \mathrm{m}$; FluX Vector ORIENTATION GIVEN IN DEGREES COUNTERCLOCKWISE FROM THE EAST; $\triangle \theta$ IN DEGREES

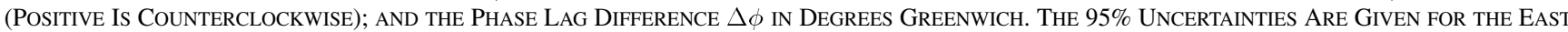

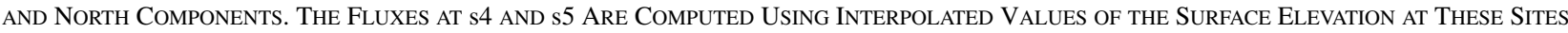

\begin{tabular}{|c|c|c|c|c|c|c|c|}
\hline 01 & $F_{X}$ & $F_{Y}$ & $F$ & $\theta$ & $\Delta \theta$ & $\Delta \phi$ & $F / F_{M A X}$ \\
\hline s2 & $0.34 \pm 0.12$ & $0.04 \pm 0.10$ & 0.35 & 6 & -118 & 108 & $64 \%$ \\
\hline $\mathrm{s} 3$ & $0.38 \pm 0.13$ & $0.16 \pm .09$ & 0.41 & 22 & -107 & 100 & $56 \%$ \\
\hline s4 & $0.64 \pm 0.28$ & $-0.02 \pm 0.37$ & 0.64 & -2 & -123 & 110 & $50 \%$ \\
\hline s5 & $0.73 \pm 0.45$ & $0.04 \pm 0.26$ & 0.73 & 3 & -122 & 102 & $35 \%$ \\
\hline s7 & $-0.79 \pm 0.36$ & $0.22 \pm 0.30$ & 0.82 & 165 & -9 & 72 & $31 \%$ \\
\hline K1 & $F_{X}$ & $F_{Y}$ & $F$ & $\theta$ & $\Delta \theta$ & $\Delta \phi$ & $F / F_{M A X}$ \\
\hline s2 & $0.27 \pm 0.12$ & $0.01 \pm 0.11$ & 0.27 & 2 & -134 & 106 & $39 \%$ \\
\hline s3 & $0.38 \pm 0.14$ & $0.31 \pm 0.09$ & 0.49 & 39 & -106 & 99 & $54 \%$ \\
\hline s4 & $0.57 \pm 0.30$ & $0.47 \pm 0.34$ & 0.74 & 39 & -98 & 94 & $41 \%$ \\
\hline s5 & $0.47 \pm 0.46$ & $0.74 \pm 0.26$ & 0.88 & 58 & -80 & 86 & $37 \%$ \\
\hline s7 & $-0.87 \pm 0.34$ & $-0.19 \pm 0.42$ & 0.89 & -168 & 31 & 69 & $41 \%$ \\
\hline M2 & $\boldsymbol{F}_{\boldsymbol{X}}$ & $F_{Y}$ & $F$ & $\theta$ & $\Delta \theta$ & $\Delta \phi$ & $F / F_{M A X}$ \\
\hline s2 & $0.12 \pm 0.04$ & $0.68 \pm 0.08$ & 0.69 & 80 & -2 & 4 & $99 \%$ \\
\hline s3 & $-0.15 \pm 0.07$ & $0.61 \pm 0.11$ & 0.63 & 104 & 7 & -13 & $97 \%$ \\
\hline s4 & $-0.34 \pm 0.08$ & $0.43 \pm 0.09$ & 0.55 & 128 & 11 & -19 & $82 \%$ \\
\hline s5 & $-0.29 \pm 0.08$ & $0.52 \pm 0.10$ & 0.60 & 119 & 37 & -40 & $94 \%$ \\
\hline s7 & $-0.66 \pm 0.09$ & $0.46 \pm 0.09$ & 0.81 & 145 & -8 & 13 & $98 \%$ \\
\hline S2 & $F_{X}$ & $F_{Y}$ & $F$ & $\theta$ & $\Delta \theta$ & $\Delta \phi$ & $F / F_{M A X}$ \\
\hline $\mathrm{s} 2$ & $-0.02 \pm 0.01$ & $0.04 \pm 0.02$ & 0.04 & 121 & 40 & -55 & $69 \%$ \\
\hline s3 & $-0.01 \pm 0.02$ & $0.03 \pm 0.04$ & 0.03 & 101 & 13 & -39 & $58 \%$ \\
\hline s4 & $-0.05 \pm 0.03$ & $0.01 \pm 0.04$ & 0.05 & 174 & 90 & -90 & $55 \%$ \\
\hline s5 & $-0.04 \pm 0.03$ & $0.01 \pm 0.04$ & 0.04 & 170 & 60 & -77 & $38 \%$ \\
\hline s7 & $-0.09 \pm 0.03$ & $0.03 \pm 0.04$ & 0.09 & 162 & -1 & 2 & $93 \%$ \\
\hline
\end{tabular}

The fluxes at s7 over the upper slope are westward, with both diurnal and M2 components having comparable amplitudes of about $10 \mathrm{~kW} / \mathrm{m}$ (Fig. 7). At s2 and s3, the diurnal fluxes are smaller and directed eastward, exhibiting a roughly $180^{\circ}$ reversal in direction across the shelf break. For both diurnal components, the magnitude of the phase lag between high water and maximum flow varied over the range from roughly $70^{\circ}$ to $110^{\circ}$, so that the flux vector was directly more toward the minor axis and the flux magnitude was reduced to roughly $30 \%-65 \%$ of its possible maximum value.

The M2 flux vector turns clockwise in the onshelf direction, consistent with the change in orientation of the semidiurnal transport ellipses (Fig. 6). Unlike the diurnal components, the M2 phase lag between high water and maximum flow was generally small $\left(-40^{\circ}\right.$ to $\left.13^{\circ}\right)$, so that the flux vector was closely aligned with the major axis $\left(-8^{\circ}\right.$ to $\left.37^{\circ}\right)$. The resulting energy flux was within $6 \%$ of its possible maximum value except at $\mathrm{s} 4$, where the reduction from maximum was $18 \%$. The general behavior of the M2 tide (especially at s2, s3, and s7 where both pressure and current were directly measured) is roughly consistent with local Sverdrup wave propagation, with high water and maximum current in phase. The onshelf turning of the M2 ellipse orientation plus the fact that the observed current ellipticity (minor axis/major axis) is larger (greater than 0.50 except 0.44 at s2) than the theoretical plane wave value of $\sigma / f=0.39$ at all sites suggest refraction of the M2 wave as it turns northward toward the Taiwan Strait. As noted before, the observed M2 surface tide northward M2 phase speed between s7 and s2 is only $45 \%$ of the theoretical value for a simple Sverdrup plane wave, indicative of more complex dynamics.

The S2 flux vector also turns clockwise in the onshelf direction; however, the phase lag between high water and maximum flow was more variable $\left(-90^{\circ}\right.$ to $\left.2^{\circ}\right)$ and the flux vector was less aligned with the transport major axis $\left(-1^{\circ}\right.$ to $\left.90^{\circ}\right)$. The resulting flux amplitudes varied from roughly $38 \%$ to $93 \%$ of their possible maximum values.

\section{DiscusSiON AND SUMMARY}

A moored array of acoustic Doppler current profilers, current meters, and bottom pressure recorders were deployed across the shelf break in the northeast SCS near $21^{\circ} 55^{\prime} \mathrm{N}, 117^{\circ} 20^{\prime} \mathrm{E}$ during April-May 2001 as part of the ASIAEX. This area was chosen in part because of strong local tidal currents, internal tides, and large-amplitude high-frequency internal waves, all of which can strongly influence sound propagation across the shelf break, one scientific focus of ASIAEX. The moored array returned sufficient current data in the vertical to allow estimation of the barotropic currents at five sites ranging in depth from 350 to $71 \mathrm{~m}$. We use harmonic tidal analysis of these depth-averaged currents and bottom pressure to describe the primary $\mathrm{O} 1, \mathrm{~K} 1, \mathrm{M} 2$, and $\mathrm{S} 2$ tidal constituents in the study area.

The tides in this area are mixed, with the $\mathrm{O} 1$ and $\mathrm{K} 1$ tidal currents dominant over the upper slope and the M2 tidal current 


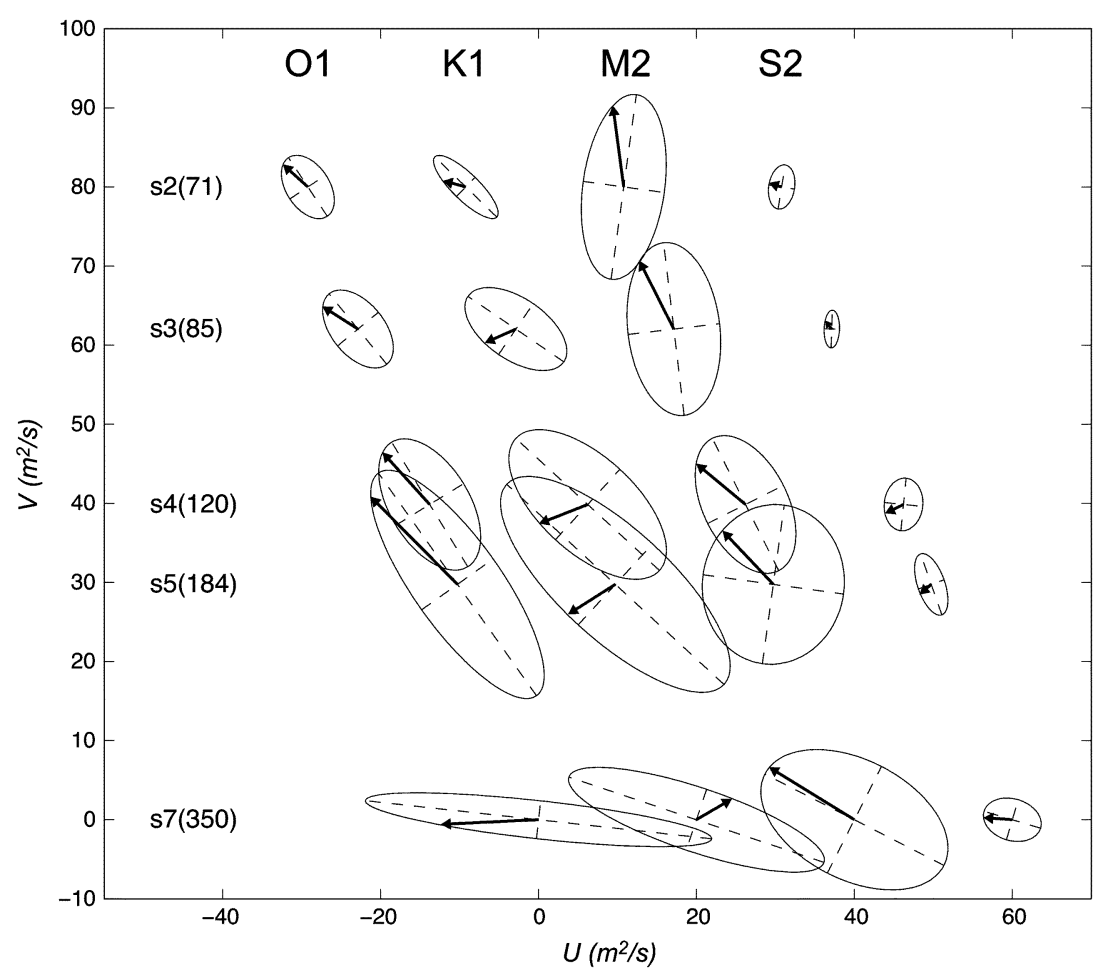

Fig. 6. O1, K1, M2, and S2 tidal transport ellipses at the ASIAEX mooring sites plotted with North up, offset origins, and a common scale to facilitate comparison. The major and minor axes denoted by dashed lines and the direction of the transport vector at zero Greenwich phase by the vector drawn from the ellipse center. The centers of the ellipses for each constituent are plotted to reflect the geographical positions of the mooring sites.

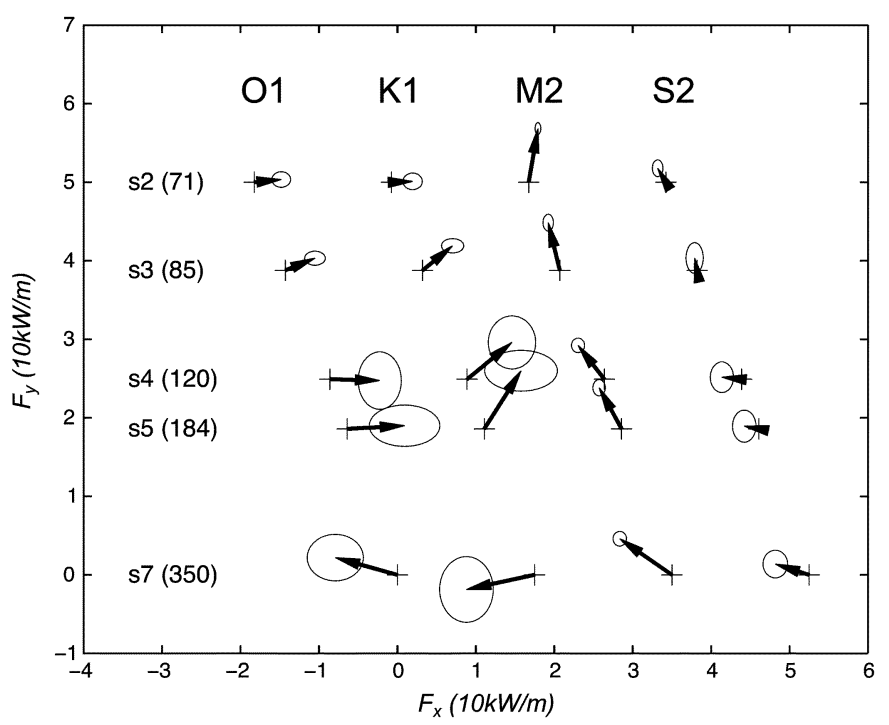

Fig. 7. O1, K1, M2, and S2 tidal energy flux vectors at the ASIAEX mooring sites plotted with North up and offset origins. The S2 flux has been enlarged by a factor of 5 to show its structure. The ellipse at the vector head indicates the $95 \%$ confidence limits of the east and north flux components, computed using a bootstrap approach and the uncertainties in the elevation and current tidal analysis for each constituents. Current and pressure were measured together only at s2, s3, and s7. The fluxes at s4 and s5 were computed using interpolated tidal elevation values.

becoming dominant over the shelf. The tidal currents are elliptical at all sites, with clockwise turning with time with the possible exception of $\mathrm{O} 1$ and $\mathrm{K} 1$ at $\mathrm{s} 7$ where the semiminor axes of these components were poorly resolved. The $\mathrm{O} 1$ and $\mathrm{K} 1$ current amplitudes tend to increase slightly northward toward the shelf break and then decrease toward shallower water over the shelf. The $\mathrm{O} 1$ and $\mathrm{K} 1$ transports decrease monotonically northward by a factor of 2 due to the sharp decrease in water depth from the deepest slope site to the shallowest shelf site. The O1 and K1 energy fluxes are directed roughly westward over the slope and eastward over the midshelf. These fluxes are roughly $30 \%-65 \%$ of their possible maximum values since the phase lag between high water and maximum transport was generally closer to $90^{\circ}$ than to $0^{\circ}$.

Duda et al. [1] use the ASIAEX moored current, temperature, conductivity (salinity), and pressure measurements to describe in detail the diurnal baroclinic tidal currents observed at s4. They estimate that the diurnal internal tide there has an average energy flux of about $1 \mathrm{~kW} / \mathrm{m}$ directed toward $330^{\circ} \mathrm{N}$. From our analysis, the combined $\mathrm{O} 1$ and $\mathrm{K} 1$ barotropic tidal energy flux at s4 is $12.9 \mathrm{~kW} / \mathrm{m}$ directed toward $70^{\circ} \mathrm{N}$, roughly perpendicular to the baroclinic energy flux. The ratio of baroclinic to barotropic energy fluxes is roughly $8 \%$, indicative of significant local generation of the internal diurnal tide. A more trustworthy demonstration of this would be a definitive measurement of the divergence of the diurnal barotropic tidal energy flux, but our data do not allow that. The bottom rises rapidly in a sequence of terraces and steps over the upper slope toward the shelf near the mooring transect. At s5, just offshore of an upward step, the bottom slope is quite large $\left(2.9^{\circ}\right)$, well exceeding the critical slopes needed for diurnal $\left(0.1^{\circ}-0.3^{\circ}\right)$ and semidiurnal $\left(0.3^{\circ}-1.0^{\circ}\right)$ internal wave generation (Appendix A).

The barotropic M2 and S2 current ellipses turn clockwise in the onshelf direction, with a clear onshelf increase in current amplitude. The M2 and S2 transport ellipses also show 

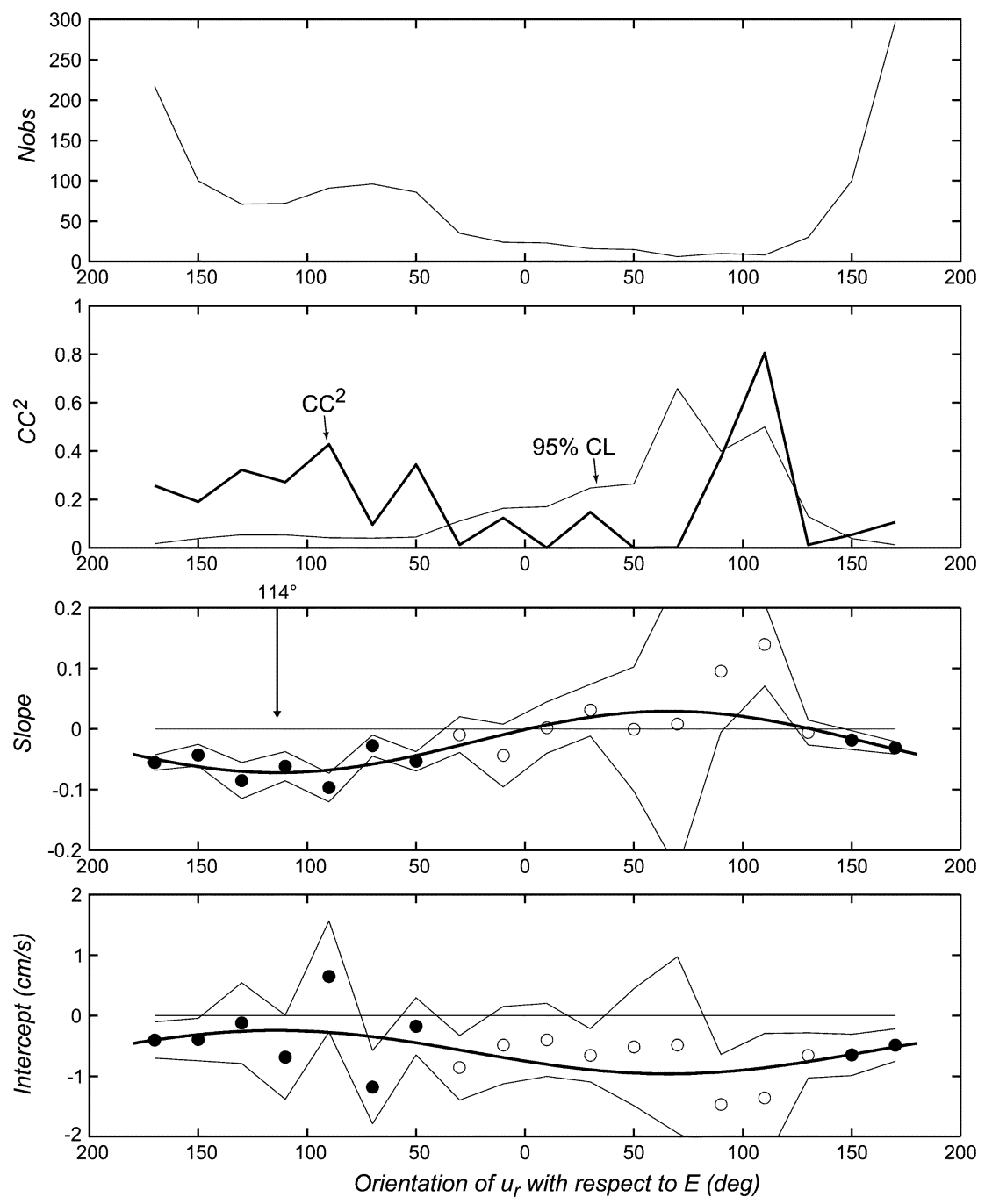

Fig. 8. Results of regression analysis of horizontal and vertical velocities in the first good ADCP depth bin closest to the bottom at s5. Top panel: number of current direction measurements in $20^{\circ}$-wide azimuthal bins. Second panel: correlation coefficient squared $\mathrm{cc}^{2}$ (thick line) and $95 \%$ confidence limit that true $c c^{2}$ exceeds 0 (thin line). Third panel: slope with $95 \%$ confidence limits, with the slope values in solid circles for those azimuthal bins where the $\mathrm{cc}^{2}$ exceeds 0 with 95\% confidence. Bottom panel: intercept. The heavy black lines in the lower two panels shows the best fit of a planar sloping bottom to the ADCP data, with the maximum negative slope occurring at an orientation of $-114^{\circ}$, as shown in the third panel. This means that the bottom slopes up toward $66^{\circ} \mathrm{CCW}$ from the east.

this clockwise veering, but with little change in amplitude, suggesting that the flow is approximately nondivergent in the direction of the ellipse (i.e., major axis) orientation. The M2 energy flux vector is generally closely aligned with the transport major axis and within $6 \%$ of its maximum value (except at $\mathrm{s} 4$, where the reduction from maximum is $18 \%$ ), a result of the small phase lag between high water and maximum transport. Thus, the M2 tide (and, to a lesser extent, the S2) appears to be turning clockwise to become more across the local isobaths as it moves northward into shallower water, as a local plane wave undergoing refraction and topographic steering yet conserving energy along its path. This accounts for the onshelf increase in M2 current components and their dominance of the tidal variance on the shelf.

The observed behavior of the barotropic K1 and M2 tides in the ASIAEX study area are consistent with the recent barotropic numerical model results of [4] and [7] in most aspects. The first study used a finite-difference model with $0.25^{\circ} \times 0.25^{\circ}$ grid resolution while the second used a spectral finite-element model with higher resolution over the continental slope. The tidal ellipse maps of [7] exhibit the clockwise turning of both $\mathrm{K} 1$ and M2 in the northward direction over the slope and shelf in the ASIAEX study area. The $\mathrm{O} 1$ and M2 energy flux maps of [4] also show clockwise turning, with the $\mathrm{O} 1$ vector turning by roughly $80^{\circ}$ from $320^{\circ} \mathrm{N}$ to $40^{\circ} \mathrm{N}$ and the $\mathrm{M} 2$ turning $60^{\circ}$ from $300^{\circ} \mathrm{N}$ to $0^{\circ} \mathrm{N}$. While the model $\mathrm{M} 2$ flux pattern agrees well with the measured flux at s7, s3, and s2, the measured $\mathrm{O} 1$ turning was almost twice that predicted.

Both models highlight the importance of the regional bathymetry, especially the presence of Taiwan and Taiwan Strait, on the propagation of tidal energy from the North Pacific. There is a strong flux of $\mathrm{O} 1, \mathrm{~K} 1$, and $\mathrm{M} 2$ tidal energy southwest through the Taiwan Strait, which converges with the northward flux from the SCS and turns east and southeast toward the southern tip of Taiwan. Including this region of convergence west of Taiwan, the Taiwan Strait is a major sink of M2 energy, roughly $14.5 \mathrm{GW}$ [4]. In comparison, the dissipation of $\mathrm{K} 1$ energy there is only $0.4 \mathrm{GW}$. The precise 
roles of bottom topography, coastline shape, and friction on the dynamics of the barotropic tides around Taiwan (including the ASIAEX study area) are not yet known.

Niwa and Hibiya [6] numerically examine the conversion of M2 barotropic to baroclinic tidal energy in the Pacific Ocean. They found that internal tide generation was concentrated in the western Pacific, especially associated with abrupt topographic changes (e.g., island arcs, shallow straits, shelf break). The net conversion rate for the topographic chain formed by the Luzon Strait, Taiwan (and its shelf to the west), the ECS shelfbreak, and the Ryukyu Island chain to the southwest end of Japan is quite large, $41 \mathrm{GW}$, roughly $12 \%$ of the total for the entire Pacific Ocean. The M2 barotropic tidal currents can reach $2 \mathrm{~m} / \mathrm{s}$ or more in the shallow Luzon Strait and are known to generate internal tides that steepen and form trains of large-amplitude highfrequency internal solitary waves that propagate west through the SCS. Orr and Mignerey [9] estimate that these "transbasin" internal waves can attain an energy flux of about $2 \mathrm{~kW} / \mathrm{m}$ toward the west in the ASIAEX study area, although this diminishes to near zero at neap tide. In comparison, the mean M2 barotropic energy flux is about $6.0 \mathrm{~kW} / \mathrm{m}$ toward $335^{\circ}$, a factor of 3 larger. The strong fluxes of tidal energy into and across the northeast SCS ensure that internal tides and large-amplitude high-frequency internal waves will be generated at the shelf edge throughout the basin, adding complexity to the local internal wave taxonomy.

\section{APPENDIX A BOTTOM SLOPE AT s5}

The s5 ADCP horizontal velocity components $u$ and $v$ near the bottom exhibit a strong correlation with the vertical component $w$. To illustrate this, the correlation coefficient squared $\left(\mathrm{cc}^{2}\right)$ was computed between $U_{R}$ (the horizontal velocity component in the direction of $\theta \pm 10^{\circ}$ with respect to the east) and $w$ for the first good depth bin above the ADCP. The number of measurements within each $20^{\circ}$ azimuthal bin is plotted in the top panel in Fig. 8, with the $\mathrm{cc}^{2}$ and $95 \%$ confidence limit that the true $\mathrm{cc}^{2}$ exceeds 0 plotted below in the second panel. The $\mathrm{cc}^{2}$ values are significant for the flow between about $170^{\circ}$ and $-50^{\circ}$, i.e., flow directed for the northeast to southwest.

This behavior can best be explained as the result of the bottom boundary condition that flow close to the bottom must be parallel to the bottom, i.e., $w=\tan (\alpha) U_{B}$ where $U_{B}$ is the horizontal velocity in the direction of maximum bottom slope $\left(\theta_{B}\right)$ and $\alpha$ is the inclination angle of the bottom, considered here to be a simple plane close to the ADCP mooring. To determine $\theta_{B}$ and $\alpha$, a least-squares fit of the model $w=\mathrm{A}+\mathrm{B} U_{B}$ was made for each $20^{\circ}$ azimuthal bin and the resulting slope $\mathrm{B}(=\tan (\alpha))$ is plotted in the third panel in Fig. 8 and the intercept $A$ in the bottom panel. This analysis gives $\theta_{B}=66^{\circ}$ counterclockwise from the east, with $\tan (\alpha)=0.051\left(\alpha=2.9^{\circ}\right)$. The amplitude of the intercept variation is $0.36 \mathrm{~cm} / \mathrm{s}$, which is quite small in comparison with the measured $w$ 's. Both values of $\theta_{B}$ and $\alpha$ seem to be appropriate in comparison with the ASIAEX topographic map [Fig. 1(b); also see [1]]. The bottom slope at s5 is quite steep, significantly greater than the critical slopes for both diurnal and semidiurnal components.

\section{ACKNOWLEDGMENT}

The authors want to thank the many individuals who made the April-May 2001 ASIAEX field program a wonderful success and who generously shared their data to form the extensive physical oceanographic and acoustic data set produced by the program. Discussions with K. Brink, G. Gawarkiewicz, C. Le Provost, and J. Lerczak helped to clarify the analysis and interpretation and J. Cook provided graphics support. This is WHOI contribution 11156.

\section{REFERENCES}

[1] T. F. Duda, J. F. Lynch, J. D. Irish, R. C. Beardsley, S. R. Ramp, C.-S Chiu, T. Y. Tang, and Y. J. Yang, "Internal tide and nonlinear internal wave behavior at the continental slope in the northern South China Sea," IEEE J. Oceanic Eng., vol. 29, pp. 1105-1130, Oct. 2004.

[2] G. D. Egbert and S. Y. Erofeeva. (2002) Efficient inverse modeling of barotropic ocean tides [Online]. Available: http://www.oce.orst.edu/po/ research/tide/otis.pdf

[3] G. Fang, J. Yang, and Y. Thao, "A two-dimensional numerical model for tidal motion in the Taiwan strait," Marine Geophys. Res., vol. 7, pp. 267-276, 1984.

[4] G. Fang, Y.-K. Kwok, K. Yu, and Y. Zhu, "Numerical simulation of principal tidal constituents in the South China Sea, Gulf of Tonkin and Gulf of Thailand," Continental Shelf Res., vol. 19, pp. 845-869, 1999.

[5] T. Hatayama, T. Awaji, and K. Akimoto, "Tidal currents in the Indonesian Seas and their effect on transports and mixing," J. Geophys. Res., vol. 101, pp. 12353-12 373, 1996.

[6] Y. Hiwa and T. Hibiya, "Numerical study of the spatial distribution of the M2 internal tide in the Pacific Ocean," J. Geophys. Res., vol. 106, no. C10, pp. 22 441-22 449, 2001.

[7] F. Lefevre, C. Le Provost, and F. H. Lyard, "How can we improve a global ocean tide model at a regional scale? A test on the Yellow Sea and the East China Sea," J. Geophys. Res., vol. 105, no. C4, pp. 8707-8725, 2000.

[8] J. F. Lynch and S. R. Ramp, "ASIAEX overview," IEEE J. Oceanic Eng., vol. 29, pp. 920-928, Oct. 2004.

[9] M. H. Orr and P. C. Mignerey, "Nonlinear internal waves in the South China Sea: Observations of the conversion of depression internal waves to elevation internal waves," J. Geophys. Res., vol. 108, p. 3064, 2003.

[10] A. L. Ye and I. S. Roberson, "Tidal dynamics in the South China Sea," Geophys. J. R. Astronom. Soc., vol. 72, pp. 691-707, 1983.

[11] F. Yin, "Tides around Taiwan," in Ocean Hydrodynamics of the Japan and East China Seas. ser. Oceanography Series, T. Ichiye, Ed. Amsterdam, The Netherlands: Elsevier, 1984, vol. 39, pp. 301-315.

[12] R. Pawlowicz, B. Beardsley, and S. Lentz, "Classical tidal harmonic analysis with error analysis in MATLAB using T_TIDE," Comput. Geosci., vol. 28, pp. 929-937, 2002.

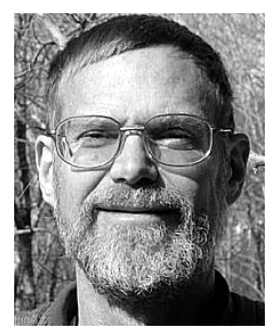

Robert C. Beardsley received the B.S degree in physics and the Ph.D. degree in physical oceanography from the Massachusetts Institute of Technology (MIT), Cambridge, MA, in 1964 and 1968, respectively.

He was a Member of Faculty in the Department of Meteorology, MIT, until 1975, when he joined the Scientific Staff, Woods Hole Oceanographic Institution, Woods Hole, MA, where he now is a Senior Scientist in the Department of Physical Oceanography. He held the Walter A. and Hope Noyes Smith Chair for Excellence in Coastal Research from 1996 to 2001 and has worked on the dynamics of continental shelf circulation, with a focus on observational and numerical model studies of wind-, tidal-, and buoyancy-driven currents; mixing; and air-sea forcing on the continental shelf and marginal seas and the impact of these processes on biological processes and ecosystem dynamics.

Dr. Beardsley is a Fellow of the American Geophysical Society and of the American Association for the Advancement of Science and is a Member of the American Meteorological Society and of the Oceanography Society. 


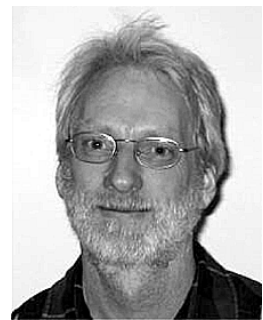

Timothy F. Duda received the B.A. degree in physics from Pomona College, Claremont, CA, in 1979 and the Ph.D. degree in oceanography from the Scripps Institution of Oceanography, University of California, San Diego, in 1986.

$\mathrm{He}$ has been a Scientist with the Woods Hole Oceanographic Institution (WHOI), Woods Hole, MA, since 1991. Prior to that, he held positions with the University of California, Santa Cruz. His three primary fields of study are ocean acoustic propagation, ocean internal gravity waves, and ocean mixing processes. He has modeled and analyzed fluctuations of ocean acoustic transmissions, has made electromagnetic-type internal-wave measurements, and performed in situ measurements of ocean microstructure.

Dr. Duda is a Member of the American Meteorological Society, the American Geophysical Union, and the Acoustical Society of America.

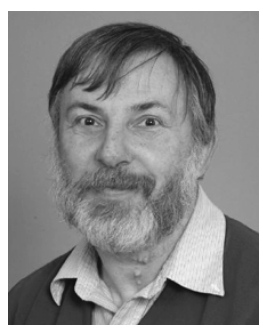

James F. Lynch (M'96-SM'03) was born in Jersey City, NJ, on June 3,1950 . He received the B.S. degree in physics from Stevens Institute of Technology, Hoboken, NJ, in 1972 and the Ph.D. degree in physics from the University of Texas, Austin, in 1978.

He was with the Applied Research Laboratories, University of Texas at Austin (ARL/UT) from 1978 to 1981 , after which he joined the scientific staff at the Woods Hole Oceanographic Institution (WHOI), Woods Hole, MA. He has been with WHOI since then and currently holds the position of Senior Scientist in the Applied Ocean Physics and Engineering Department. His research specialty areas are ocean acoustics and acoustical oceanography, but he also greatly enjoys occasional forays into physical oceanography, marine geology, and marine biology.

Dr. Lynch is a Fellow of the Acoustical Society of America and Editor-inChief of the IEEE JOURNAL OF OCEANIC ENGINEERING.

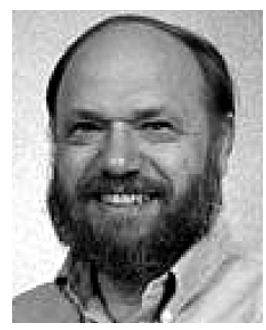

James D. Irish received the B.S. degree in physics from Antioch College, Yellow Springs, OH, in 1967 and the $\mathrm{Ph} . \mathrm{D}$. degree in oceanography from the Scripps Institution of Oceanography, La Jolla, CA, in 1971.

He currently is a Senior Research Specialist in the Department of Applied Ocean Physics and Engineering, Woods Hole Oceanographic Institution (WHOI), Woods Hole, MA. His work has included tides, internal waves, bottom pressure observations, coastal circulation, sediment transport, acoustic instrumentation, instrument testing and evaluation, buoys and moorings, and offshore aquaculture instrumentation and engineering. His research interests include developing and deploying new instrumentation, especially with telemetry to observe the ocean.

Dr. Irish is a Member of the American Geophysical Union, the Marine Technology Society, and the Oceanographic Society.

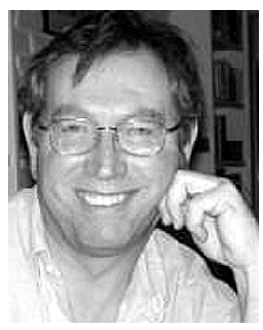

Steven R. Ramp received the M.S. degree in physical oceanography from the University of Washington, Seattle, in 1976, and the Ph.D. degree in physical oceanography from the University of Rhode Island, Narragansett, in 1986.

Since 1986, he has been with the U.S. Navy as a Professor at the Naval Postgraduate School, Monterey, CA, and a Program Officer at the Office of Naval Research, Arlington, VA. Prior to this, he spent time at the National Marine Fisheries Service, Woods Hole, MA. His research specialty is ocean observations from both ships and oceanographic moorings, and he has organized major expeditions to the Japan Sea, East China Sea, and South China Sea. He was the International Scientific Coordinator for the Asian Seas International Acoustics Experiment (ASIAEX).

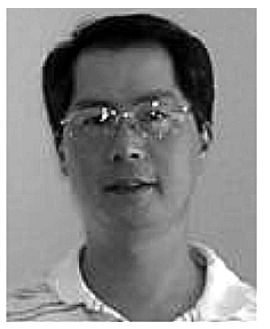

Ching-Sang Chiu received the Ph.D. degree from the Massachusetts Institute of Technology/Woods Hole Oceanographic Institution, Woods Hole, MA (MIT-WHOI) joint program in 1985.

He is a Professor of oceanography with the Naval Postgraduate School, Monterey, CA. His research specialties include ocean acoustics, acoustical oceanography, and coastal ocean processes and their influences on acoustics prediction. He has authored or coauthored more than 40 refereed publications in those subject areas.

Dr. Chiu is a Fellow of the Acoustical Society of America and Editor-in-Chief of the Journal of Computational Acoustics.

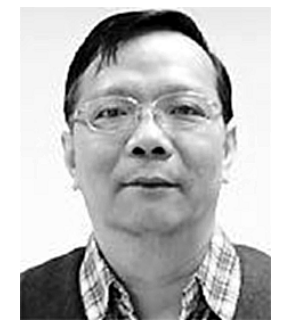

Tswen Yung Tang was born in Taiwan, R.O.C., in 1952. He received the M.S. degree in physical oceanography from National Taiwan University, Taipei, Taiwan, in 1975 and the Ph.D. degree in physical oceanography from North Carolina State University, Raleigh, in 1984.

In August 1993, he was appointed Professor of Physical Oceanography at the Institute of Oceanography, National Taiwan University. He was appointed Program Manger of the Division of Marine Science, National Science Council, Taiwan, in January 2004. His research interests include equatorial dynamics, variability of upstream of Kuroshio, Kuroshio intrusion at Luzon Strait, circulation in the South China Sea, and internal waves.

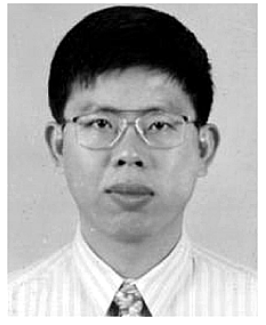

ical Union.
Ying-Jang Yang was born in Taiwan, R.O.C., in 1967. He received the B.S. degree in oceanography from National Taiwan Ocean University in 1990, and the $\mathrm{Ph} . \mathrm{D}$. degree in physical oceanography from the National Taiwan University in 1996. He is currently an Assistant Professor in the Department of Marine Science, Chinese Naval Academy, Kaohsiung, Taiwan. His research interests include internal tides and waves, current variation around Taiwan, and equatorial dynamics.

Dr. Yang is a Member of the American Geophys-

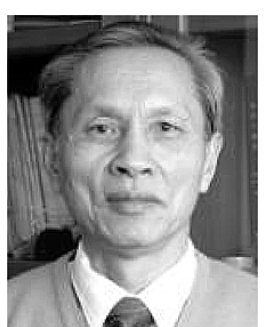

Guohong Fang graduated in 1961 from the Department of Physics, Nankai University, Tianjin, China.

$\mathrm{He}$ joined the Scientific Staff with the Hebei Institute of Oceanology, Tianjin, and transferred to the Institute of Oceanology, Chinese Academy of Sciences, Qingdao, in 1964. In 2003, he joined the First Institute of Oceanography, State Oceanic Administration, Qingdao, China. He has been a Research Professor at both Institutes since 1986. He has worked on ocean tides and marginal sea circulation, with his main interests including analysis and modeling of ocean tides, the theory of tides in shelf seas, and circulation in the East and South China Seas.

Dr. Fang was awarded the National Natural Science Prize in 1990 and the National Science and Technology Advancement Prize in 1992. He is a Member of the Board of Directors in both the Chinese Society of Oceanography and the Chinese Society of Oceanology and Limnology and serves as Chairman of the Committee for Ocean Tides and Sea Level. He also is a Member of the American Geophysical Union. 